\title{
Health and Health-related Problems in a Cohort of Apprentices in Switzerland
}

\author{
J.-F. HOLTZ and M.-A. BOILLAT \\ Institute of Occupational Health Sciences, University of Lausanne, Switzerland
}

\begin{abstract}
Summary
Out of a cohort of 1200 apprentices in Switzerland, 781 boys and 417 girls completed a questionnaire on their perceived health and health problems in their selected apprenticeship. Each participant was interviewed afterwards by the school nurses in three state-owned professional schools where the apprentices attended their classes. Ninety-five per cent of the respondents enjoyed excellent health, 28 cases had neryous system or psychological problems, 17 cases had problems of a locomotor nature, 12 subjects had gastrointestinal or endocrinological symptoms, and there was one with a past history of a malignant disease. Twelve cases also had respiratory symptoms or diagnoses. One hundred and nineteen apprentices reported that they had been troubled by the workplace. Exposure to solvents, chemicals in general, dust, smoke and noise were often mentioned as causes. Thirty-eight of them had contacted their family physician in connection with these problems. The cohort had experienced, mostly during their first year, 191 cases of accident necessitating medical care. Cuts, shocks and falls were the most common occurrences. Meat cutters and butchers had the highest frequency of accidents. Near-accidents had been experienced so far by 46 per cent of the respondents. At the interviews, school nurses provided counsel and intervened in flagrant cases of occupational risks. It seems that an ordinary medical certificate does not predict accident-proneness or possible medical problems, while in-school health programmes could provide rapid intervention and support.
\end{abstract}

\section{Introduction}

Many countries require medical certificates from prospective students of professional schools and academies. Excellent general health is indispensable for commercial pilots, complete eye sight and colour vision are needed in locomotive engineers, and substance abuse is probably not a desirable feature of a future public security or law-enforcement agent. Apart from these glaring examples, the need for a medical certificate for more common trades remains debatable. Some views regard for example preemployment screening only as ornamental ${ }^{1}$ and an initial involvement of a physician is probably not always necessary. This might have been caused by the shift of the disease spectrum from chronic, infectious diseases, like tuberculosis, to other less easily detectable ailments with completely different natural histories ${ }^{2}$. Another aspect is that the primary medical health care provider might be more urgently needed elsewhere ${ }^{3}$ than in certifying health which does not seem to predict morbidity very well ${ }^{1}$.

The Canton of Vaud in Switzerland provides an apprenticeship programme for its youth containing at any time some 14000 participants. They are admitted from the junior high school at the age of 15-16 years, although a small minority come from senior high school or from college. These students take part in practical work in accepted firms and attend classes in state-owned schools. Attending the programme requires a medical certificate of aptitude by law, although its nature is not described more closely. The cantonal authorities have only recently formulated a standardized questionnairebased certificate with the objective that the certificates would be of a more uniform standard, as it is known that checklists upgrade the quality of medical records ${ }^{4}$.

In connection with this project and to gain insight into the personal and occupational health problems in modern industry and trades, a questionnaire study was carried out among apprentices enrolled in the state-provided programme and attending at the time of the study classes in three professional schools, in three different towns of the Canton. The general idea was to structure the standardized medical examination towards the most prevalent occupational problems.

The aim of this study was to gain information on the state of health experience by the apprentices, to have some idea of the health problems affecting them, perceived risks, occupational accidents and near accidents and to give counsel on health matters to the subjects and, on a group basis, to their teachers. At a more strategic level, the results will be used for the structured medical examination required by the state schools, and furthermore, the cohort will be followed-up as to the predictive value of, for example, accident proneness in the apprentice schools.

\section{Subjects and Methods}

A total of 1200 apprentices were selected from various occupations for which the school nurses were interested, based on their experience with potential risks. The distribution of their occupations is considered to be fairly representative of the local trades, except that agriculture could not be included.

Half of the 1200 apprentices of the study attended the professional school of the city of Lausanne, 29 per cent came from Yverdon and 21 per cent from Vevey; 781 were boys and 417 were girls. The mean age of respondents was $17 \pm 2$ years $( \pm$ S.D). Half of the apprentices had left the junior high school, 20 per cent had left the senior high school and the rest had higher school records or other school backgrounds. Over 80 per cent of the respondents were in their first year of apprenticeship, and over 70 per cent were attached to firms employing $1-20$ persons (Fig. 1).

The standardized questionnaire was filled in mostly in classrooms by the students, and afterwards school nurses interviewed each person individually to clarify the replies and to discuss the health problems mentioned. The participation was excellent. Only two questionnaires of qualified participants were not included in the analysis because of incomplete data, and one person refused to complete the form.

In devising the questionnaire (Appendix), the following ideas were taken into account. A strict anonymity would 

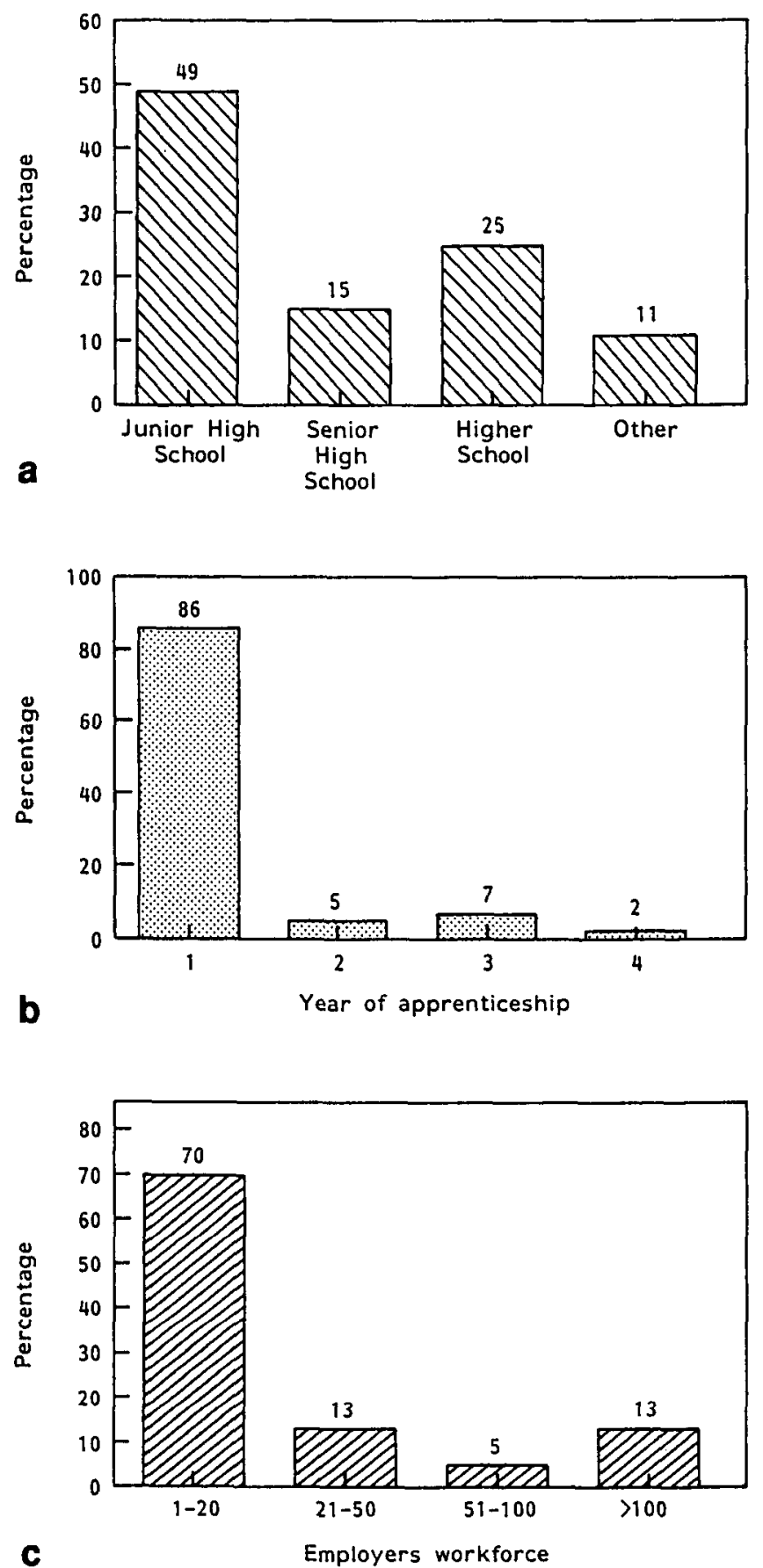

Fig. 1. Scholarity (a), seniority in the apprenticeship programme (b) and size of participating firms in terms of their salaried employees (c)

be observed at all times. Most questions should be answered by ticking the appropriate box only, and finally, the completion should not take more than $10 \mathrm{~min}$. The questions followed on logically one from another and no 'dummy' questions were included. However, when coding the replies for computer analysis, the logic of responses was inspected. All in all, the questionnaires contained over 95 individual points covering medical history to current health problems and occupational hygiene aspects at the place of work. All interviews were carried out between 1 October 1987 and 1 February 1988.

The responses were coded mostly as yes or no, medical diagnoses were always noted and finally sum frequencies were noted without comparison of classes, while the students were regrouped according to their trade or industry.

\section{Results}

Ninety-five per cent (1143 of 1200) felt that they enjoyed good health. For the remaining 52 cases ( 4 per cent) the neurological reasons and psychological reasons ( 28 cases) were the commonest causes in stating otherwise. Specifically, ten had migraine, two had epilepsy, two had chronic vertigo, and one had had meningitis. As to the psychological problems, five said that they were constantly 'nervous', five had chronic fatigue, and one each was depressed, insomniac or had a bad memory.

Seventeen subjects had symptoms in their locomotor apparatus. Nine of them had backaches, and six leg pains. Two subjects had had knee operations for trauma. Almost as often (12 cases), respiratory problems were indicated. They included two asthmatics and two other unspecified dyspnoea states. One each had intercurrent head cold, hay fever or unspecified allergy. Two had chronic nasal drip and three others did not specify their respiratory problems more closely.

As to the gastrointestinal or endocrinological problems, three had intestinal pains, one had gastritis, two had diabetes and two were grossly overweight (over 130 per cent of their calculated ideal weight). Two further cases had hypertension, and one had been operated on for seminoma.

Ten per cent of those surveyed (119 persons) thought that the work had affected their health, and 38 (3.2 per cent) of them had for this reason contacted their family physician. These cases did not include the 191 accidents experienced by the 1200 apprentices, mostly during their first year, and which had necessitated medical interventions (Table I). Cuts were most frequent (59 times). Foreign bodies and toxic splashes in eyes, shocks and loss of balance were each reported over 40 times (Table I). Burns, falls, trapped legs or hands and electric shocks were less frequent occurrences (Table I).

Butchers and meat cutters were clearly at greatest risk (Table II), followed by locksmith and mechanic apprentices.

Table I. Type of accidents to apprentices

\begin{tabular}{lr}
\hline Accidents & Number \\
\hline Cuts & 59 \\
Foreign bodies in eyes & 44 \\
Shock & 43 \\
Loss of balance & 42 \\
Burns & 28 \\
Falls & 16 \\
Trapped legs or hands & 13 \\
Electric shocks & 6 \\
Others & 31 \\
Total & 191 \\
\hline
\end{tabular}

Table $I$. Frequency of accidents according to occupation

\begin{tabular}{lcc}
\hline Occupation & Number of apprentices & $\begin{array}{c}\text { Positive answers } \\
(\%)\end{array}$ \\
\hline Butcher and meat cutter & 16 & 62.5 \\
Locksmith & 67 & 37.3 \\
Storeman & 13 & 30.8 \\
Mason & 20 & 30 \\
Mechanic operator & 4 & 25 \\
Carpenter & 66 & 22.7 \\
\hline
\end{tabular}


Carpenters seemed to have less accidents than others. Thirty-nine per cent of the 1200 surveyed said that they had experienced near-accidents up to four times and five per cent had the same experience up to nine times. Fifty-four per cent had never been close to a personal accident. Firms employing less than 20 persons were more frequently associated with accidents requiring medical care than bigger firms ( 18 vs. $12 \%, p<0.01$ chi $^{2}$ test). The same held true for near accidents ( 51 vs. $38 \%$, respectively, $p<0.001$ chi $^{2}$ test ).

The subjects had also noted temporary health problems which they associated with their work but without being severe enough to merit a medical consultation. Seven hundred and sixteen cases of occasional backaches were reported; leg pain, 299 cases; stress, 217 cases; sight problems, 113 cases; headaches, 106 cases; dermatological problems, 88 cases; epigastric pain, 80 cases; drunken feeling, 76 cases; and upper respiratory tract problems, 156 cases.

The feeling of drunkenness was mostly associated with the exposure to solvent vapours, and it was reported by 47 per cent of floor layers and 32 per cent of painters. Other trades included cosmetic workers, sealers and decorators. Apart from solvents, the apprentices were worried about the use of chemicals in general (35 per cent of all), of dust ( 25 per cent), of smokes ( 20 per cent), of noise ( 20 per cent) and of microbial agents ( 10 per cent). Other worries were climatization (18 per cent), visual display units ( 8 per cent) and vibrations ( 5 per cent).

Sixty-one per cent ( 734 subjects) said that they had been informed of the possible health risks; 607 of them thought that the information was sufficient. This means that half of the surveyed apprentices thought that they had not been adequately informed of the health risks associated with their work. There was no difference in the information received as to the health hazard between smaller (less than 20 employed) and bigger firms.

Sixty-five per cent of the apprentices were obliged to wear personal protective devices, i.e. masks, glasses or gloves. Ten per cent did not have any of those items at their disposal even if found necessary by themselves. The latter groups included 69 per cent of the stable boys, 46 per cent of floor layers, 26 per cent of masons, 17 per cent of butchers, 14 per cent of bakers, 14 per cent of foresters and lumberjacks and 12 per cent of hairdressers. Seventy-eight per cent of all respondents often or always used personal protectors, 15 per cent used them occasionally and 3 per cent never used them (Fig. 2). The size of the

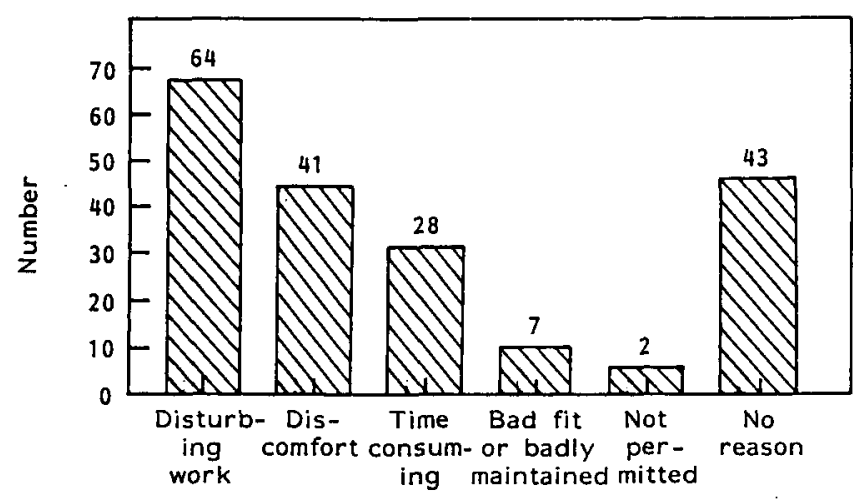

Fig. 2. Reasons for non-compliance in the use of protective devices.

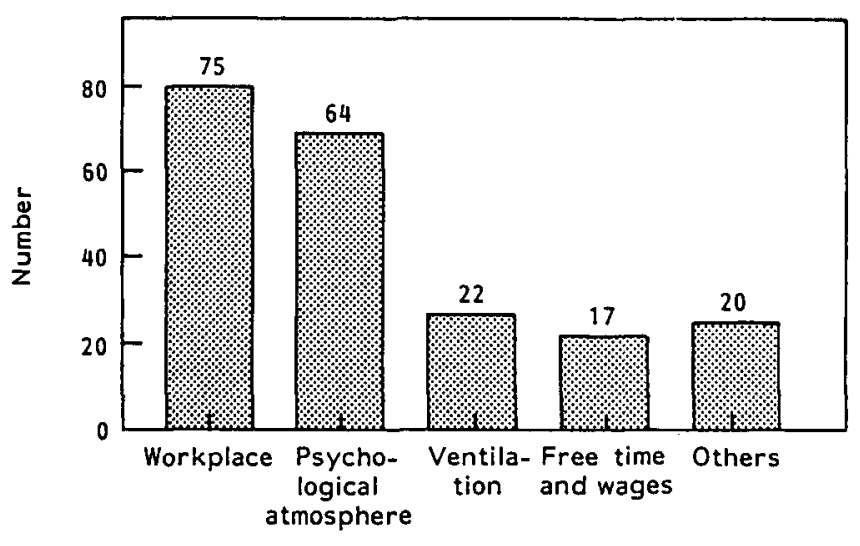

Fig. 3. Apprentices' causes of dissatisfaction.

firm was not an influential factor in complying with the use of protective devices.

Twenty per cent of the apprentices thought that their conditions could be improved. This view was shared by 21 per cent of all boys and 23 per cent of all girls. Specific suggestions included general improvement of workplaces, improvement of psychological atmosphere, improvement of ventilation, increase of pay and free time (Fig. 3).

\section{Discussion}

So far, exclusion from a desired apprenticeship on medical grounds seems to have been almost non-existent compared to, for example, the policy of exclusion of atopic persons from the Finnish school of dental technicians ${ }^{5}$. The selection of trade or industry has mostly been guided by personal interest and academic aptitude. Family traditions may play a role although probably wages and current fashionable trends can be major factors. It is unlikely that a youth under 20 years of age seriously considers a possible occupational health hazard in a rather distant future as a factor in making his decision, although a competitive school system may already create stress and negative affectivity ${ }^{6}$.

This study was an open-ended investigation in so far as the respondents did not receive other information than health counselling from nurses, and the responses were not compared from one class to another. The three schools did not offer all available study lines in the Canton, so that no comparisons between the schools, and necessarily geographical areas, were made. Likewise, although planned by the cantonal medical authority, the study was supervised only by nurses at the local level so that no new medical diagnostics were made. Therefore, the frequency of medical problems found in this study corresponds mostly to medical conditions already known to the specific participant. This obviously results in a bias because the answering of autobiographical questions can be selective for memory ${ }^{7}$ and psychological reasons.

For this age group, the announced smoking and drinking habits are almost certainly under-reported for obvious reasons.

As a major number of the apprentices are junior high school leavers and also from artisan or working class families, the representatives of the highest social classes may be few. As important associations with the health status and social class exist, it would be important to have family data for comparison. This proved to be impossible as it would have intruded too deeply into the 
family sphere, which would not have been accepted by the families and would possibly have caused loss of confidence on the part of the students themselves. Anyway, social class is mostly determined by the family income and schooling ${ }^{8}$, factors most likely comparable in this study population.

This questionnaire study was completed with interviews by nurses specialized in the health problems of adolescents about to enter the adult working life. Although much is known of the specific health outcomes in a plethora of industries and trades, surprisingly little data are available on this age group. Although the figures found by the surveys are relevant for a European economy and industry, they are also subject to various social and cultural variables.

Social class status and its association with health has already been pointed out above. Another point is that a profession is not always selected in accordance with personal wishes but because a few professions enjoy higher status and are more sought after. Electricians, for example, enjoy this status, and the selection is mostly based on grades won in the previous school. The health of the children of low-income families tends to be worse than that of others ${ }^{9}$ which might also affect academic performance $^{10}$. This probably introduces an element of bias in the comparison of the various apprentice groups ${ }^{11}$.

As this study did not specifically try to verify the volunteered information, it is quite likely that memory bias and other personal factors may render some of the figure less than absolute. For example, only one case of past malignant disease was reported by the 1200 respondents. This is not very surprising, as it is known that a substantial proportion of long-term survivors of childhood cancer do not reveal their past medical history ${ }^{12}$.

Another aspect not verified by actual measurements is the exposure data. However, this might be less prone to erroneous reporting as, for example, a good correlation exists between the exposure declared by pregnant women in a questionnaire study with that actually detected ${ }^{13}$. The frequency of the occupational hazards as reported by the apprentices might actually be higher than that experienced by older workers, who have probably already been subject to selection by the so-called 'healthy worker effect' or who are otherwise inured to the harmful substances they come into contact with daily.

The health enjoyed by Swiss youth seems to be comparable to that of earlier studies. In a study of 8883 East-Germans of 14 to 25 years of age, 70 per cent indicated that they had no medical problems ${ }^{14}$. Principal deviations in the remaining 30 per cent included troubles of vision, of the musculoskeletal system and of the respiratory tract. In a Dutch study on 14- to 18-year-old job applicants, a very similar frequency of health complaints as in our study was found ${ }^{15}$. The author considers his number unrealistically optimistic as respondents tend to omit, for psychological reasons and for the reasons discussed above, part of minor or socially compromising problems.

As to the spectrum of medical problems, our data agree very well with an earlier Swiss study on the results of the required medical examinations of the apprentices ${ }^{16}$. Back problems, nervousness, hay fever and headaches were the most frequently reported problems in that study and found by the physician in an examination. These findings and our data are at variance with the known prevalence of, for example, asthma in children (38 per $1000^{17}$, vs.
2 per 1200 in this study) while frequency of diabetes $(1.8 / 1000$ vs. $2 / 1200)$ and seizure disorders $(3.5 / 1000$ vs. $2 / 1200$ ) are close to each other ${ }^{17}$.

Ten per cent of respondents in our study felt that their health was affected by the workplace factors, and one third of them thought that the problems warranted a medical opinion. As to the main body of the reported health problems, it seems that medical help was not required because of their transient nature, and/or because they occurred only during work and did not intrude on leisure time. The latter attitude may have led to their acceptance as an aspect of life comparable to smoking, drinking or drug habit known by the majority as deleterious to health. Social pressure may also work in this direction as, for example, "no-one is considered a qualified electrician without his or her electric shock'.

Even allowing for this tradition, the accident rates are high, although it is known that young men of 16-24 years of age are more accident-prone than others ${ }^{18}$.

This figure is also close to data published by the Swiss Insurance for Accidents remarking that the first year of employment is the period with the highest prevalence of occupational injuries. It is estimated that 150000 Swiss people have an accident annually at home ${ }^{19}$, which is 3 to 5 times less than the frequency of accidents among the group of apprentices. In this respect, our study proved to be useful preventatively as the interviewing nurses could immediately give counsel or undertake remedial action.

It seems that a medical examination before the enrolment in a state-provided apprenticeship programme does not aid greatly in the avoidance of eventual problems in the actual apprenticeship. Most problems may be related to the socio-economic realities of the families as well as to the cultural traditions. The greatest prevalence of psychological and neurological problems might be the ones to which special attention should be paid. Smoking, drinking and drug habits may be predictors, in this increasing order, of a problematic and unsuccessful apprenticeship. They may also show tendencies to fatalistic risk taking and alienation. It would seem that an in-school health care system ${ }^{20}$ which can rapidly intervene, is preferable to generalist- or hospital-provided services.

\section{Acknowledgements}

We thank Mrs V. Hervy, N. Bottin, G. Capt, M.-L. Gabathuler, F. Lanini, A. Maziaro, C. Schmidt, J. Annaheim, Dr P.-A. Michaud, M. D., Dr Ph. Hotz, M. D., and Prof. H. Savolainen, M.D., for their help and cooperation. We would also like to thank all the participants in this study.

\section{REFERENCES}

1. Houghton A, Edmondson-Jones JP, Harris LA. Pre-employment screening: use of ornament? J Soc Occup Med 1989; 39: 51-5.

2. Fries JF. Aging, illness and health policy: implications of the compression of morbidity. Perspect Biol Med 1988; 31: 407-28.

3. Mulhausen R, McGee J. Physician need, an alternative projection from a study of large, prepaid group practices. $J A M A 1989 ; 261$ : 1930-34.

4. Cheney C, Ramsdell J. Effect of medical records' checklists on implementation of periodic health measures. Am J Med 1987; 83: $129-36$.

5. Rajaniemi R, Tola S. Subjective symptoms among dental technicians exposed to the monomer methyl methacrylate. Scand $J$ Work Environ Health 1985; 1: 2816. 
6. Watson D, Pennebaker JW. Health complaints, stress and distress: exploring the central role of negative affectivity. Psychol Rev 1989; 96: 234-54.

7. Bradburn N, Rips LJ, Shevell SK. Answering autobiographical questions: the impact of memory and inference on surveys. Science 1987; 236: $157-61$

8. Liberatos P, Link B, Kelsey J. The measurement of social class in epidemology. Epidemiol Rev 1988; 10: 87-121.

9. Shah C, Kahan M, Krauser J. The health of children of low-income families. Can Med Assoc J 1987; 137: 485-90.

10. Cadman D, Ealter S, Chambers L, Ferguson R, Szatmar P, Johnson N, McNamee J. Predicting problems in school performance from preschool health, developmental and behavioral assessments. Can Med Assoc $J$ 1988; 139: 31-6.

11. Hartman B, Reum PJ. Studie zum Gesundheitszustand von jugendlichen Lehrlingen verschiedener Berufsgruppen. $Z$ Ges Hyg Grenzgeb 1981; 27: 69-72.

12. Byrne J, Lewis S, Halamek L, Connelly R, Mulvihill J. Childhood cancer survivors' knowledge of their diagnosis and treatment. Ann Int Med 1989; 110: 400-3
13. Eskenazi B, Pearson K. Validation of a self-administered questionnaire for assessing occupational and environmental exposures of pregnant women. Am J Epidemiol 1988; 128: 1117-29.

14. Hartman B, Nehring R, Reum PJ. Gegenstand, Zielstellung und erste Ergebnisse des arbeitsmedizinischen Jugendforschung in der DDR. Z Ges Hyg Grenzgeb 1979; 25: 750-5.

15. Nijenhuis HWA. The health of adolescents. A survey of the state of health of 14 to 18-years old applicants for a job in the Netherlands. Int Arch Occup Environ Health 1977; 40: 209-24.

16. Ritzel G, Lietha R. Evaluation der im Rahmen der Berufsbildungsgesetzes durchgeführten medizinischen Untersuchungen von Lehrlingen. Schw Rundsch Med (Praxis) 1977; 66: 1645-50.

17. Gortmaker SL, Sapenfield W. Chronic childhood disorders: Prevalence and Impact. Pediatr Clin North Am 1984; 31: 3-26.

18. Health and Safety Executive. Accident at work. Lancet 1987; ii: 1288.

19. Boillat MA. Les accidents domestiques. Cah Med Soc 1988; 32: 179-82.

20. Council Report. Providing medical services through school-based health programs. JAMA 1989; 26: 1939-42.

\section{Appendix}

Questionnaire

You are invited to complete this personal questionnaire which will be treated confidentially. It will only be examined by the nurse who distributed it to you and the physicians of the Institute of Occupational Health Sciences (Lausanne).

1. Generally speaking, do you feel in good health?

If no, which disease are you suffering from?

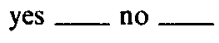

2. Do you think that your health is at the present time unfavourably influenced by your work?

Did you consult a physician in this connection?

Comment briefly:

3. Have you ever had a work injury which had to be treated ?

If yes, write the number of times in the appropriate box

(e.g. 1 means once)

- slipping, skidding, false step

- fall from height

- trapped limb

_ - burn (heat, chemical)

- impact with an objec

- electric shock

- splinter or splash in eye

- cut needing suture

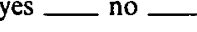

yes

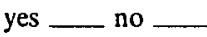

4. Since you started your apprenticeship, how many times were you close to having an accident (narrow escape) ?

never __ $\quad 1-4$ times _ $\quad 5-9$ times __ more than 9 times

5. Do you have one or more of the following problems at work?

- skin problems

- irritation of eyes __ nose ___ throat

- breathing difficulty (e.g. asthma)

- stomach or abdominal pain

- back pain (more than once a month)

neck __ mid-back ___ lower back

- arms and shoulder pain

- leg pain (including heavy feeling)

- headache (more than once a week)

- drunkenness, 'floating sensation' in

contact with various products

- nervousness (stress, atmosphere)

- others, explain:

6. In the occupation you will be carrying out, do you feel that the following substances, agents or jobs may be a risk to your health ?

- chemicals

- dusts

- fumes

- noise

- poor air-conditioning

- vibrations

- microbes, virus

- visual display terminals

- dactylography

- others, explain

\begin{tabular}{|c|c|}
\hline yes & no \\
\hline yes & no \\
\hline yes & no \\
\hline yes & no \\
\hline yes & no \\
\hline yes & no \\
\hline yes & no \\
\hline yes & no \\
\hline & \\
\hline
\end{tabular}


28 OCCUPATIONAL MEDICINE (1991) VOL. 41/NO. 1

7. In your classes or from your supervisor at work, did you receive any information on the risks in your occupation?

If yes, do you feel you have been sufficiently informed

yes no no n__

yes $\longrightarrow$ no

yes $\_$no $\_-$

(e.g. masks, glasses, gloves) ?

If yes, are these items at your disposal?

When the situation requires it, do you wear them ?

$$
\text { always __ often __ rarely ___ never }
$$

If you answered 'never' or 'rarely', specify why:

hinders my work __ poor maintenance

takes time $\quad$ not allowed

uncomfortable _ _ other reason, explain:

9. Is there anything it is absolutely necessary to improve

at your work place?

If yes, explain:

yes _ no

Initial of first name

Date of birth Day

Initial of last name

Last school attended? Month Year $\operatorname{Sex} M-F$ in State:

Which occupation are you learning ?

Current year of apprenticeship: first second third fourth

Number of employees in your firm:

$$
\begin{aligned}
& 1-20 \\
& 51-100
\end{aligned}
$$

What is the main activity of your firm (e.g. construction, bank):

Requests for reprints should be addressed to: Dr M.-A. Boillat, Associate Professor, IUMHT, rue du Bugnon 19, CH-1005 Lausanne, Switzerland. 